\title{
Cloning and sequence analysis of cDNA for human renin precursor
}

\author{
(hypertension/aspartyl proteinase/sequence homology/recombinant DNA/kidney)
}

\author{
TaKashi Imai*, Hitoshi Miyazaki*, Shigehisa Hirose*, Hitoshi Hori*, TaKashi Hayashi*, \\ RYoichiro Kageyama ${ }^{\dagger}$, Hiroaki OHKubo ${ }^{\dagger}$, Shigetada NaKanishi ${ }^{\dagger}$, AND \\ KAZUO MURAKAMI ${ }^{*}$
}

*Institute of Applied Biochemistry, University of Tsukuba, Ibaraki 305, Japan; and IInstitute for Immunology, Kyoto University Faculty of Medicine, Kyoto 606, Japan

Communicated by Hitoshi Kihara, August 24, 1983

\begin{abstract}
The primary structure of human renin precursor has been deduced from its cDNA sequence. A library of cDNA clones was constructed from human kidney $\operatorname{poly}(A)^{+}$RNA by applying the vector/primer method of Okayama and Berg. The library was screened for human renin sequences by hybridization with the previously cloned mouse renin cDNA. Of the 240,000 colonies screened, 35 colonies that were positive for hybridization were isolated. Two recombinant plasmids containing long inserts of about 1,300 and 1;600 base pairs were selected for sequence analysis. The amino acid sequence predicted from the cDNA sequence shows that the human renin precursor consists of $\mathbf{4 0 6}$ amino acids with a pre and a pro segment carrying 20 and 46 amino acids, respectively. A high degree of sequence homology was found upon comparison of the mouse and human renins. Close similarities were also observed in the primary structures of renin and aspartyl proteinases that have known three-dimensional structures, suggesting a similar tertiary structure for renin.
\end{abstract}

The renin-angiotensin system plays an important role in the regulation of blood pressure and electrolyte balance $(1,2)$. Activation of the system is initiated by the release of the enzyme renin from the kidney into the bloodstream, where it acts on its substrate to produce angiotensin I. The decapeptide angiotensin I is subsequently converted to angiotensin II, an octapeptide that causes marked vasoconstriction of arteriolar smooth muscle and stimulates aldosterone secretion in the adrenal cortex. Because the aspartyl proteinase renin is the initial and the rate-limiting component of the system, there has been considerable interest in the study of this enzyme, yet progress in elucidating the biochemical properties of renin, especially human renin, has been slow because of the limited supply of human kidneys and minute quantities of renin present in the kidney. Although the use of sophisticated methods of protein purification and characterization has circumvented these potential problems to some extent and improved the knowledge on renin significantly, precise identification of the structure of the renin molecule has not been achieved yet. For example, there are conflicting reports on the molecular weight and the amino acid composition of human renin (3-6).

Comparative biochemical studies have revealed that human renin is unique among other animal renins in its molecular properties such as $\boldsymbol{M}_{\mathrm{r}}, \mathrm{pI}$, and antigenicity (3). The renin-substrate reaction is also species dependent (7); renin isolated from the kidneys of monkeys and humans reacts with angiotensinogens from all mammals, whereas renin from other mammals does not release angiotensin I from angiotensinogen of monkeys and humans. To establish a molecular and genetic basis for the differences in the biochemical properties as well as to de-

The publication costs of this article were defrayed in part by page charge payment. This article must therefore be hereby marked "advertisement" in accordance with 18 U.S.C. \$1734 solely to indicate this fact. termine the amino acid sequence of human renin, attempts were made to obtain full-length cDNA clones from poly $(\mathbf{A})^{+}$RNA extracted from a surgically removed ischemic kidney in which the renin content was markedly increased due to the stenosis of the renal artery.

The results presented here describe the cloning and sequence analysis of human renin cDNAs. The entire $3^{\prime}$ noncoding sequence preceding the poly(A) tail, 1,218 nucleotides coding for renin precursor, and 42 nucleotides of the $5^{\prime}$ noncoding region were determined.

\section{MATERIALS AND METHODS}

Materials. Materials were obtained from the following sources: terminal deoxynucleotidyltransferase and T4 polynucleotide kinase from Takara Shuzo (Kyoto, Japan); Escherichia coli DNA polymerase I and E. coli DNA ligase from New England BioLabs; restriction enzymes from Takara Shuzo and New England BioLabs; $E$. coli RNase $H$ from P-L Biochemicals; $\left[\gamma^{32} \mathrm{P}\right]$ ATP $\left(>5,000 \mathrm{Ci} / \mathrm{mmol} ; 1 \mathrm{Ci}=3.7 \times 10^{10} \mathrm{~Bq}\right)$ and $\left[\alpha_{-}{ }^{32} \mathrm{P}\right] \mathrm{dCTP}$ $(\approx 3,000 \mathrm{Ci} / \mathrm{mmol}$ ) from Amersham.

Construction of a Human Kidney cDNA Library. Total RNA, which originated from a kidney removed from a patient with severe renovascular hypertension causing renal ischemia, was extracted in $4 \mathrm{M}$ guanidine thiocyanate buffer as described by Chirgwin et al. (8). Poly(A) ${ }^{+}$RNA was prepared by subjecting the total RNA preparation to oligo(dT)-cellulose column chromatography twice (9). A cDNA library was constructed by applying the method of Okayama and Berg (10), using $22 \mu \mathrm{g}$ of poly $(\mathrm{A})^{+} \mathrm{RNA}$ and $5.6 \mu \mathrm{g}$ of vector/primer DNA. After transformation of $E$. coli $\mathrm{HB101}$, the cells were plated on nitrocellulose filters on ampicillin-containing agar plates (11).

Identification of Human Renin cDNA Clones. The human kidney cDNA library was screened by colony hybridization using a nick-translated Acc I/Rsa I fragment (358 base pairs) from renin cDNA of a mouse submandibular gland (12). Prehybridization was performed at $55^{\circ} \mathrm{C}$ in $50 \mathrm{mM}$ Tris $\cdot \mathrm{HCl}, \mathrm{pH} 7.6 / 10$ $\mathrm{mM}$ EDTA/1 M NaCl/0.2\% polyvinylpyrrolidone/0.2\% Ficoll $/ 0.2 \%$ bovine serum albumin $/ 60 \mu \mathrm{g}$ of denatured $E$. coli DNA per ml. Hybridization was carried out at $55^{\circ} \mathrm{C}$ for $18 \mathrm{hr}$ in the same buffer containing a ${ }^{32} \mathrm{P}$-labeled probe $\left(1 \times 10^{8} \mathrm{cpm} /\right.$ $\mu \mathrm{g})$. Filters were washed six times with an excess of $0.3 \mathrm{M} \mathrm{NaCl} /$ $0.03 \mathrm{M}$ sodium citrate $/ 0.1 \% \mathrm{NaDodSO}_{4}$ at $37^{\circ} \mathrm{C}$.

The clones with renin cDNA insert were selected for DNA sequence analysis by the method of Maxam and Gilbert (13).

All of the cloning procedures were conducted in accordance with the guidelines for research involving recombinant DNA molecules issued by the Ministry of Education, Science and Culture of Japan.

\footnotetext{
‡To whom reprint requests should be addressed.
} 
Blot Hybridization Analysis. The poly $(\mathrm{A})^{+}$RNAs from human liver and infarcted kidney were denatured with glyoxal (14) and electrophoresed on $1.5 \%$ agarose gel. The separated RNAs were transferred to diazobenzyloxymethyl-paper according to the procedure of Alwine et al. (15). The diazo paper was prehybridized at $42^{\circ} \mathrm{C}$ for $24 \mathrm{hr}$ in $50 \%$ (vol/vol) formamide/0.75 M $\mathrm{NaCl} / 0.075 \mathrm{M}$ sodium citrate/50 mM sodium phosphate buffer, $\mathrm{pH}$ 7.0/0.02\% polyvinylpyrrolidone/0.02\% Ficoll/0.02\% bovine serum albumin/1\% glycine/ $0.2 \% \mathrm{NaDodSO}_{4} / 100 \mu \mathrm{g}$ denatured salmon sperm DNA per ml. The paper was hybridized at $42^{\circ} \mathrm{C}$ for $24 \mathrm{hr}$ in the same solution except that glycine was omitted and that the solution contained a ${ }^{32} \mathrm{P}$-labeled probe (nick-translated Ava II fragment containing nucleotides 170 1,127 from clone $\mathrm{pHRn} 321$ ). After the hybridization, the paper was washed at $42^{\circ} \mathrm{C}$ in $0.45 \mathrm{M} \mathrm{NaCl} / 0.045 \mathrm{M}$ sodium citrate/ $0.1 \% \mathrm{NaDodSO}_{4}$ and subjected to autoradiography.

\section{RESULTS}

Construction, Selection, and Characterization of Human Renin cDNA Clones. Poly $(\mathrm{A})^{+}$RNA was isolated by oligo(dT)cellulose chromatography and used for cDNA synthesis and cloning. Initial extraction of total RNA was carried out by the guanidine thiocyanate method of Chirgwin et al. (8) to isolate intact RNA. From $26 \mathrm{~g}$ of an infarcted human kidney, approximately $66 \mathrm{mg}$ of RNA was obtained. Passage of the total RNA over an oligo(dT)-cellulose column gave a $5 \%$ yield of poly $(\mathrm{A})^{+}$ RNA. The presence of intact renin mRNA in this preparation was confirmed by cell-free translation of the poly $(\hat{\mathbf{A}})^{+}$RNA in the presence of $\left[{ }^{35} \mathrm{~S}\right]$ methionine. Immunoprecipitation of translation products with antirenin antibody and analysis of the radioactive precipitates by $\mathrm{NaDodSO}_{4} /$ polyacrylamide gel electrophoresis and fluorography revealed one major specific band with a $M_{\mathrm{r}}$ of 45,000 (data not shown).

A library of cDNA clones was constructed from the human renal poly $(\mathrm{A})^{+}$RNA by using the vector/primer method of Okayama and Berg (10), which provides a highly efficient means for obtaining full-length cDNAs. Initially, the library was screened for human renin sequences by hybridization with a 358-base-pair Acc I/Rsa I restriction fragment obtained from the previously cloned mouse renin cDNA (12). Of the 50,000 colonies screened, 6 colonies positive for hybridization were isolated. Recombinant plasmids from the selected colonies were prepared, digested with various restriction enzymes, and elec- trophoresed in agarose gels to determine the size. The insert, which contained $800-1,300$ base pairs, seemed unable to cover the entire coding sequence since mRNA coding for a $M_{\mathrm{r}} 45,000$ protein is expected to have at least 1,400 nucleotides, including $5^{\prime}$ and $3^{\prime}$ noncoding sequences; in fact, this was proved to be the case by later sequence analysis (Fig. 1) and blot hybridization analysis (Fig. 3). To isolate longer cDNAs, therefore, 190,000 colonies were further screened by using the Taq I (390)/ Taq I (630) restriction fragment (Fig. 1) excised from the longest human renin cDNA insert (pHRn011) cloned above, and 29 clones positive for hybridization were recovered. Size analysis of their inserts indicated that one recombinant plasmid, pHRn321, contained an insert with about 1,600 base pairs. This clone and the pHRn011 cDNA clone were subjected to sequence analysis.

Nucleotide Sequence Analysis. The sequences of two different clones were determined to verify the absolute fidelity of the cDNA sequence as a copy of the mRNA. The insert from pHRn011 and pHRn321 was analyzed with a series of restriction enzymes. Fig. 1 shows the restriction map and sequence analysis strategy. The complete nucleotide sequence of the longer clone (pHRn321) determined by the chemical degradation method is shown in Fig. 2. The entire sequence was obtained from both the message and complementary strands. There was complete agreement in the nucleotide sequences obtained from the overlapping areas. The insert contained 1,459 nucleotides and the length of the poly(A) tail was not included in this determination. The DNA sequence of the shorter insert, pHRn011, was found to be identical with that of the corresponding region of pHRn321. The cDNA insert of pHRn32l contained $42 \mathrm{nu}$ cleotides in the $5^{\prime}$ noncoding region, 1,218 nucleotides in the coding region, and 199 nucleotides in the $3^{\prime}$ untranslated region preceding the poly(A) tail. From this information it was possible to analyze most of the structure of human renin mRNA. The $5^{\prime}$ and $3^{\prime}$ untranslated regions of the mRNA share many of the features already noted in other eukaryotic mRNA sequences; for example, the nucleotide sequence around the initiation codon is consistent with the sequence ${ }_{\mathrm{G}}^{\mathrm{A}}-\mathrm{N}-\mathrm{N}-\mathrm{A}-\mathrm{U}-\mathrm{G}-\mathrm{G}$, which has been shown to be most favored for eukaryotic initiation sites (18). The $3^{\prime}$ untranslated region contains, in the expected position [ 20 nucleotides upstream from the poly(A) tail], the hexanucleotide $5^{\prime}$-A-A-U-A-A-A-3' which could function as a signal for poly(A) addition or termination of transcription (19).

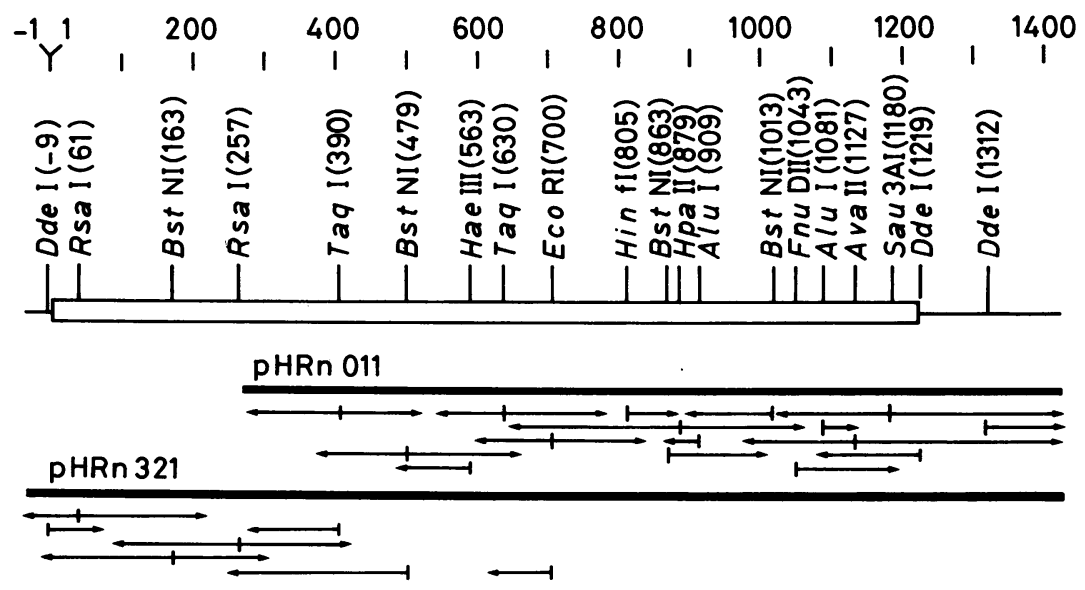

Fig. 1. Sequence analysis strategy of the human renin cDNA clones. For the isolation of clone pHRn011, see the text. For the isolation of clone pHRn321, cDNA library was rescreened by hybridization at $68^{\circ} \mathrm{C}$ with the nick-translated Taq I fragment containing nucleotides $390-630$ from clone pHRn011. The sequence corresponding to the coding region is indicated by the open box. Only the positions of the relevant restriction sites are indicated (for the nucleotide numbers, see Fig. 2). The poly (dA)-poly(dT) and poly(dG).poly(dC) tails are not included in the map. The horizontal arrows indicate the direction and extent of sequence determination. The sites of $5^{\prime}$-end-labeling are indicated by short vertical lines on the arrows. 


\section{-42 AACCTCAGTGGATCTCAGAGAGAGCCCCAGACTGAGGGAAGC -1}

1 ATG GAT GGA TGG AGA AGG ATG CCT CGC TGG GGA CTG CTG CTG CTG CTC TGG GGC TCC TGT ${ }^{\searrow} 60$ Met Asp Gly Trp Arg Arg $\underset{\{-60\}}{\text { Met }}$ Pro Arg Trp Gly Leu Leu Leu Leu Leu $\underset{\{-50\}}{\operatorname{Trp}}$ Gly Ser Cys

61 ACC TTT GGT CTC CCG ACA GAC ACC ACC ACC TTT AAA CGG ATC TTC CTC AAG AGA ATG CCC 120 Thr Phe Gly Leu Pro Thr ${ }_{\{-40\}}^{\text {Asp }}$ Thr Thr Thr ${ }_{30}$ Phe Lys Arg Ile Phe Leu ${ }_{\{-30\}}^{\text {Lys }}$ Arg Met Pro 40

121 TCA ATC CGA GAA AGC CTG AAG GAA CGA GGT GTG GAC ATG GCC AGG CTT GGT CCC GAG TGG 180

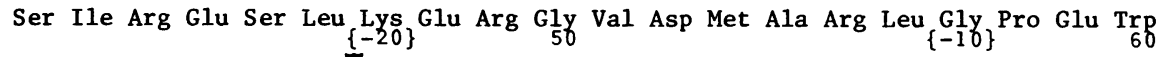

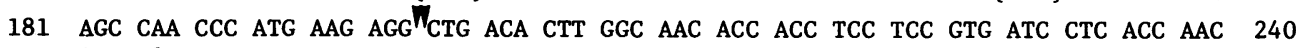
Ser Gln Pro Met Lys Arg Leu Thr Leu G1y Asn Thr Thr Ser Ser $\underset{\{-1\}\{1\} \text { Val Ile Leu Thr Asn }}{\{10\}}$

241 TAC ATG GAC ACC CAG TAC TAT GGC GAG ATT GGC ATC GGC ACC CCA CCC CAG ACC TTC AAA 300

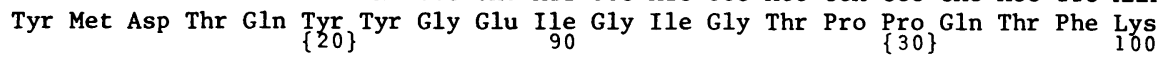

301 GTC GTC TTT GAC ACT GGT TCG TCC AAT GTT TGG GTG CCC TCC TCC AAG TGC AGC CGT CTC 360 Val Val Phe Asp Thr $\underset{\{4}{G 1 y\}}$ Ser Ser Asn Val Trp Val Pro Ser Ser Lys ${ }_{110}$ Cys Ser Arg Leu

361 TAC ACT GCC TGT GTG TAT CAC AAG CTC TTC GAT GCT TCG GAT TCC TCC AGC TAC AAG CAC 420 Tyr Thr Ala Cys Val $\underset{\{60\}}{\text { Tyr }}$ His Lys Leu Phe Asp Ala Ser Asp Ser $\underset{\{30}{\operatorname{Ser}}$ Ser Tyr Lys $\underset{130}{\text { His }}$

421 AAT GGA ACA GAA CTC ACC CTC CGC TAT TCA ACA GGG ACA GTC AGT GGC TTT CTC AGC CAG 480 Asn Gly Thr Glu Leu $\underset{\{80\}}{\operatorname{Thr}}$ Leu Arg Tyr $\underset{150}{\text { Ser }}$ Thr Gly Thr Val Ser $\underset{\{90\}}{G 1 y}$ Phe Leu Ser ${ }_{160}^{\text {G1n }}$

481 GAC ATC ATC ACC GTG GGT GGA ATC ACG GTG ACA CAG ATG TTT GGA GAG GTC ACG GAG ATG 540

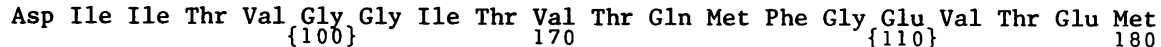

541 CCC GCC TTA CCC TTC ATG CTG GCC GAG TTT GAT GGG GTT GTG GGC ATG GGC TTC ATT GAA 600

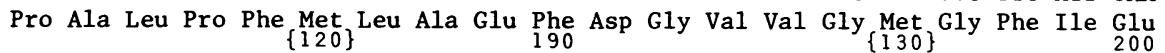

601 CAG GCC ATT GGC AGG GTC ACC CCT ATC TTC GAC AAC ATC ATC TCC CAA GGG GTG CTA AAA 660 Gln Ala Ile Gly Arg $\underset{\{140\}}{\mathrm{Val}}$ Thr Pro Ile Phe Asp Asn Ile Ile Ser ${ }_{\{100\}}^{G 1 n_{0}}$ Gly Val Leu Lys

661 GAG GAC GTC TTC TCT TTC TAC TAC AAC AGA GAT TCC GAG AAT TCC CAA TCG CTG GGA GGA 720 Glu Asp Val Phe Ser $\underset{\{160\}}{\text { Phe }}$ Tyr Tyr Asn Arg Asp Ser Glu Asn Ser $\underset{230}{G 170\}}$ Ser Leu Gly ${ }_{240}^{\text {Gly }}$

721 CAG ATT GTG CTG GGA GGC AGC GAC CCC CAG CAT TAC GAA GGG AAT TTC CAC TAT ATC AAC 780 G1n Ile Val Leu Gly ${ }_{\{180\}}$ Ser Asp Pro Gln His Tyr Glu Gly Asn $\underset{\{190\}}{\text { Phe }}$ His Tyr Ile Asn

781 CTC ATC AAG ACT GGT GTC TGG CAG ATT CAA ATG AAG GGG GTG TCT GTG GGG TCA TCC ACC 840 Leu Ile Lys Thr Gly $\underset{\{200\}}{\text { Val }}$ Trp Gln Ile Gln Met Lys Gly Val Ser $\underset{\{210\}}{\text { Val Gly Ser Ser }} \underset{280}{\operatorname{Th}}$

841 TTG CTC TGT GAA GAC GGC TGC CTG GCA TTG GTA GAC ACC GGT GCA TCC TAC ATC TCA GGT 900 Leu Leu Cys Glu Asp $\underset{\{220\}}{G 1 y}$ Cys Leu Ala Leu Val Asp Thr Gly Ala $\underset{\{290}{\operatorname{Ser}}$ Tyr Ile Ser ${ }_{30}$ Ty

901 TCT ACC AGC TCC ATA GAG AAG CTC ATG GAG GCC TTG GGA GCC AAG AAG AGG CTG TTT GAT 960 Ser Thr Ser Ser Ile $\underset{\{240\}}{G 1 u}$ Lys Leu Met ${ }_{310}$ Ala Leu Gly Ala Lys $\underset{\{250\}}{\text { Lys }}$ Arg Leu Phe ${ }_{32}$

961 TAT GTC GTG AAG TGT AAC GAG GGC CCT ACA CTC CCC GAC ATC TCT TTC CAC CTG GGA GGC 1020 Tyr Val Val Lys Cys $\underset{\{260\}}{A s n}$ Glu Gly Pro Thr Leu Pro Asp Ile Ser $\underset{\{270\}}{\text { Phe }}$ His Leu Gly ${ }_{340}^{\text {Gly }}$

1021 AAA GAA TAC ACG CTC ACC AGC GCG GAC TAT GTA TTT CAG GAA TCC TAC AGT AGT AAA AAG 1080

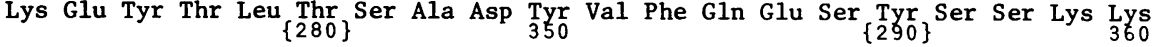

1081 CTG TGC ACA CTG GCC ATC CAC GCC ATG GAT ATC CCG CCA CCC ACT GGA CCC ACC TGG GCC 1140

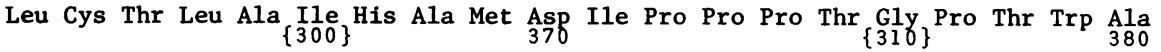

1141 CTG GGG GCC ACC TTC ATC CGA AAG TTC TAC ACA GAG TTT GAT CGG CGT AAC AAC CGC ATT 1200 Leu Gly Ala Thr Phe ${ }_{\{320\}}^{\text {Ile }}$ Arg Lys Phe Tyr Thr Glu Phe Asp Arg $\underset{\{330\}}{\text { Arg }\}}$ Asn Asn Arg $\underset{400}{\text { Ile }}$

1201 GGC TTC GCC TTG GCC CGC TGAGGCCCTCTGCCACCCAGGCAGGCCCTGCCTTCAGCCCTGGCCCAGAGCTGGA 1273 Gly Phe Ala Leu Ala $\left.{ }_{\{348}^{\text {Arg }}\right\} 406$

1274 ACACTCTCTGAGATGCCCCTCTGCCTGGGCTTATGCCCTCAGATGGAGACATTGGATGTGGAGCTCCTGCTGGATGCGT 1352

1353 GCCCTGACCCCTGCACCAGCCCTTCCCTGCTTTGAGGACAAAGAGAATAAAGACTTCATGTTCAC

FIG. 2. Nucleotide and corresponding amino acid sequence of plasmids pHRn321 and pHRn011 encoding human renal preprorenin. Nucleotides are numbered in the 5'-to-3' direction, beginning with the first residue of the ATG triplet encoding the initiator methionine, and the nucleotides on the $5^{\prime}$ side of residue 1 are indicated by negative numbers. The deduced amino acid residues are indicated below the nucleotide triplets. The mature polypeptide begins at the Leu residue labeled $\{1\}$. The numbers in the braces refer to amino acid positions within the mature renin. The single and double arrowheads indicate the probable ends of leader sequence and prosequence, respectively, as predicted by comparison with the mouse renin precursor (16) and human prepepsinogen (17). The two active-site aspartic acid residues, potential $N$-glycosylation sites, and the AA-T-A-A-A sequence within the 3 ' untranslated region are underlined.

Predicted Amino Acid Sequence of Human Renin. The amino acid sequence deduced from the nucleotide sequence analysis is shown in Fig. 2. At the $\mathrm{NH}_{2}$ terminus is a sequence of hy- drophobic amino acids characteristic of the signal peptides found in the precursors of many secreted proteins. The two adjacent basic residues, Lys-Arg at position 65-66, may represent the 


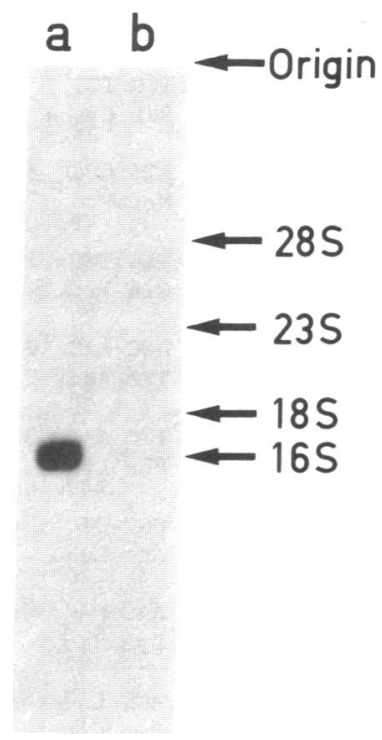

Fig. 3. Blot hybridization analysis of liver and kidney mRNA. Lane a was obtained with $10 \mu \mathrm{g}$ of poly $(\mathrm{A})^{+} \mathrm{RNA}$ from human kidney, whereas lane $b$ had corresponding quantities of human liver poly $(A)^{+}$RNA. The positions of the size markers ( $E$. coli and human ribosomal RNAs) are indicated.

site of proteolytic cleavage upon the conversion of prorenin to mature renin; the presence of prorenin was suggested by the finding that human kidney contains inactive renin that can be activated by trypsin. The molecular weight $\left(M_{\mathrm{r}}=37,200\right.$; sugar residues not included) calculated from the predicted sequence is in agreement with that determined by Yokosawa et al. (3) for the purified protein. The mature protein is composed of 340 amino acid residues: Ala, 16; Arg, 10; Asp, 17; Asn, 12; Cys, 6; Glu, 16; Gln, 12; Gly, 34; His, 6; Ile, 22; Leu, 28; Lys, 15; Met, 8; Phe, 19; Pro, 13; Ser, 33; Thr, 30; Trp, 3; Tyr, 17; and Val, 23.

Codon utilization for human renin is not random and exhibits a marked preference for codons ending with $G$ or $C$. For example, while 20 codons for valine end in $G$ or $C$, only four end in $A$ or $\mathrm{T}$; similarly for leucine, the codons with $\mathrm{G}$ or $\mathrm{C}$ in the third position occur 8 times more frequently than the codons ending in $\mathrm{A}$ or $\mathrm{T}$. Such a nonrandom codon usage has been observed in other animal genes (20).

Identification and Size Determination of Renin mRNA by Blot Hybridization Analysis. Takahashi and Tang (21) have recently shown that bovine cathepsin $\mathrm{D}$ and renin from the mouse submandibular gland are unexpectedly similar in their amino acid sequences. Therefore, to confirm that the cloned pHRn321 is complementary to renin mRNA and not to cathepsin D and to determine the size of human renin mRNA, cloned cDNA was used as a probe to hybridize to mRNA isolated from human kidney, a major source of renin, and from the liver, an abundant source of cathepsin D. As anticipated, the probe hybridized only to kidney mRNA (Fig. 3). On the basis of its migration in a denaturing gel system, it was estimated that the sequence of mature human renin $\mathrm{mRNA}$ is 1,600 nucleotides long. A protein with 406 amino acid residues requires 1,218 bases for its coding sequence. The renin mRNA must, therefore, have about 380 noncoding bases, including the $3^{\prime}$-poly(A) tail.

\section{DISCUSSION}

Emphasis was placed on the study of human renin, which is involved in the pathogenesis of several forms of hypertension. Human kidney renin is a key enzyme in the control of blood pressure as well as water and electrolyte balance. Its nucleotide and amino acid sequences had not been analyzed previously. The selection of transformants containing sequences corresponding to human renin was greatly facilitated by the availability of the defined cDNA of the mouse submandibular renin, which has previously been shown to cross-hybridize with human genomic DNA. Since the primary sequence of human renin was unknown, the final confirmation of the identity of the clones was obtained by determining the sequences of the cDNA inserts and comparing the derived amino acid sequences with the published sequences of the renin CDNA of the mouse submandibular gland (16). A considerable degree of homology was thus found between the amino acid sequences of the two enzymes, as discussed below.

Recently the primary structure of the renin of the mouse submandibular gland has been determined independently by Misono et al. (22) and Panthier et al. (16) through chemical sequence analysis of purified protein and sequencing of a cDNA clone, respectively. Comparison of the sequence of human renin with these published sequences (Fig. 4) suggests that certain regions of renin are highly conserved between the two species, particularly the regions corresponding to the functional domains that contain catalytically important aspartic acid residues, such as Phe-Asp-Thr-Gly-Ser at amino acid positions 3741 (numbering refers to mature human renin) and Val-Asp-ThrGly (residues 225-228). The overall homology for the amino acid sequences of renin isolated from human kidney and mouse submandibular gland, including the signal peptides, is $68 \%$, while the nucleotide sequences show a $76 \%$ homology. The major difference observed is that, in contrast to the renin from the mouse submandibular gland, the renin from human kidney contains

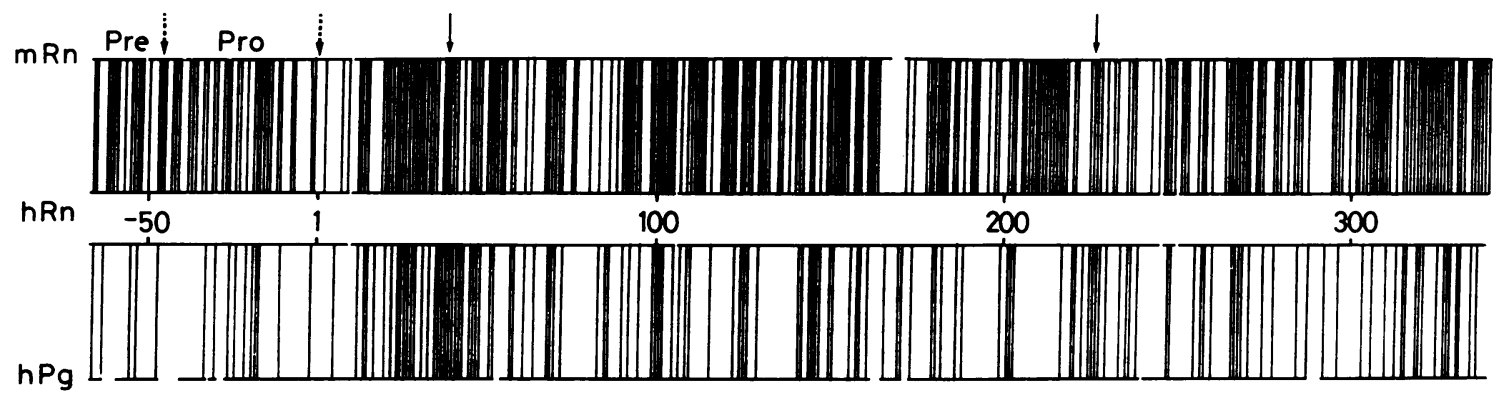

FIG. 4. Amino acid sequence homologies between human kidney renin ( $\mathrm{hRn}$ ), mouse submandibular gland renin ( $\mathrm{mRn}$ ), and human pepsinogen $(\mathrm{hPg})$. The mouse renin and the human pepsinogen sequences are derived from Panthier et al. (16) and Sogawa et al. (17) publications, respectively. Positions of homology are indicated by vertical bars. The numbers refer to amino acid positions within the mature human renin. The blank spaces in the three sequences were introduced to maximize the homology. The percentage of homologous positions for the two comparisons are: $h R n-m R n$, $68 \%$; and $\mathrm{hRn}-\mathrm{hPg}, 34 \%$. Broken arrows represent the sites of proteolytic cleavage upon the conversions of preprorenin to prorenin and of prorenin to mature renin. Arrows indicate the catalytically important residues: Asp-38 and Asp-226. 
the amino acid sequence Asn-X-Thr (residues 5-7 and 75-77; numbering refers to the mature protein), which could be potential glycosylation sites.

$\mathrm{X}$-ray crystallographic studies of aspartyl proteinases (22-25) have revealed unique structural features common to all the members of this family. The molecule is bilobal, with two approximately equal domains separated by a deep and long cleft that serves as the substrate binding site. Each domain has a similar folding of the peptide chain and forms a wall-like structure of mixed $\beta$-sheet surrounding the cleft. The two catalytically important aspartic acid residues are centrally located in the cleft. To obtain a rough image of the secondary and tertiary structures of human renin, we compared the primary structure of renin with that of other aspartyl proteinases, whose structures are well defined. The comparison revealed that $(i)$ a considerable degree of homology exists between renin and other aspartyl proteinases (45-60\%) and (ii) many of the identical residues are located in the surroundings of the cleft, particularly in the regions corresponding to the active site aspartates. It seems reasonable, therefore, to assume that the common structural features of aspartyl proteinases are also present in renin.

Knowledge of renin has recently become very detailed but confusing. Multiple forms of active renin have been extracted from kidneys of several species (26). The probability that these renins are the products of separate renin genes seems to be very low because all the human renin cDNAs cloned in this study yielded identical patterns of restriction fragments when digested with Ava II, Rsa I, or BstNI and analyzed by electrophoresis. Therefore, the different forms of renin may result from posttranslational modifications or more likely represent a mere experimental artifact induced by limited proteolysis during the extraction and purification procedures. In support of this view, four cleavage sites with two basic amino acids $\left(\mathrm{Lys}^{250}-\mathrm{Arg}^{251}\right.$, $\mathrm{Lys}^{293}-\mathrm{Lys}^{294}, \mathrm{Arg}^{321}-\mathrm{Lys}^{322}$, and $\mathrm{Arg}^{329}-\mathrm{Arg}^{330}$ ) are known to occur near the $\mathrm{COOH}$ terminus of mature renin. In addition to the active renins, inactive renins that can be activated by trypsin have been demonstrated in human kidneys and plasma. Biochemical characterizations have suggested that inactive renin in the kidney corresponds to prorenin, a biosynthetic precursor of renin. However, the relationship between the renal prorenin and the inactive material in plasma, which accounts for more than $80 \%$ of the total plasma renin, is not clear (for reviews see refs. 27-29). Attempts to show that inactive renin in plasma is a precursor of the circulating active renin have produced conflicting results, and currently available data do not allow one to determine whether the plasma inactive renin represents the prorenin secreted from the kidney or the previously active renin covalently combined with an inactivating protein. It is anticipated that the size and the amino acid sequence of the pro segment reported here may contribute to a more precise analysis of the exact nature of plasma inactive renin.

Recent studies that have demonstrated the presence of renin in several organs other than the kidney have modified the classic assumption that the renin-angiotensin system is a system of renal origin that regulates blood pressure. Especially, renin from the brain has drawn a great deal of attention because it is im- plicated in the regulation of numerous activities of the central nervous system $(30,31)$. Full-length renin cDNAs cloned here could serve as useful probes for the cloning of extrarenal renin cDNAs as well as for the analysis of the organization and expression of human renin genes.

We thank Drs. Yasumi Ohshima, Kunio Yamane, and Norihiro Okada for their helpful suggestions and Kenichi Matsumoto for his technical assistance. This study was supported in part by research grants from the Ministry of Education, Science and Culture of Japan, the Itoh Science Foundation, and the Japan Heart Foundation.

1. Oparil, S. \& Haber, E. (1974) N. Engl. J. Med. 291, 389-401.

2. Peach, M. J. (1977) Physiol. Rev. 57, 313-370.

3. Yokosawa, H., Holladay, L. A., Inagami, T., Haas, E. \& Murakami, K. (1980) J. Biol. Chem. 255, 3498-3502.

4. Galen, F.-X., Devaux, C., Guyenne, T., Menard, J. \& Corvol, P. (1979) J. Biol. Chem. 254, 4848-4855.

5. Slater, E. E. \& Strout, V., Jr. (1981) J. Biol. Chem. 256, 8164-8171.

6. Higaki, J., Hirose, S., Ogihara, T., Imai, N., Kisaragi, M., Murakami, K. \& Kumahara, Y. (1983) Life Sci. 32, 1591-1598.

7. Fasciolo, J. C., Leloir, L. F., Munoz, J. M. \& Braun-Menendez, E. (1940) Science 92, 554-555.

8. Chirgwin, J. M., Przybyla, A. E., MacDonald, R. J. \& Rutter, W. J. (1979) Biochemistry 18, 5294-5299.

9. Aviv, H. \& Leder, P. (1972) Proc. Natl. Acad. Sci. USA 69, 14081412.

10. Okayama, H. \& Berg, P. (1982) Mol. Cell. Biol. 2, 161-170.

11. Morrison, D. A. (1979) Methods Enzymol. 68, 326-331.

12. Masuda, T., Imai, T., Fukushi, T., Sudoh, M., Hirose, S. \& Murakami, K. (1982) Biomed. Res. 3, 541-545.

13. Maxam, A. M. \& Gilbert, W. (1980) Methods Enzymol. 65, 499560 .

14. McMaster, G. K. \& Carmichael, G. G. (1977) Proc. Natl. Acad. Sci. USA 74, 4835-4838.

15. Alwine, J. C., Kemp, D. J. \& Stark, G. R. (1977) Proc. Natl. Acad. Sci. USA 74, 5350-5354.

16. Panthier, J.-J., Foote, S., Chambraud, B., Strosberg, A. D., Corvol, P. \& Rougeon, F. (1982) Nature (London) 298, 90-92.

17. Sogawa, K., Fujii-Kuriyama, Y., Mizukami, Y., Ichihara, Y. \& Takahashi, K. (1983) J. Biol. Chem. 258, 5306-5311.

18. Kozak, M. (1981) Nucleic Acids Res. 9, 5233-5252.

19. Proudfoot, N. J. \& Brownlee, G. G. (1976) Nature (London) 263, 211-214.

20. Wain-Hobson, S., Nussinov, R., Brown, R. J. \& Sussman, J. L. (1981) Gene 13, 355-364.

21. Takahashi, T. \& Tang, J. (1983) J. Biol. Chem. 258, 6435-6443.

22. Misono, K. S., Chang, J.-J. \& Inagami, T. (1982) Proc. Natl. Acad. Sci. USA 79, 4858-4862.

23. Tang, J., James, M. N. G., Hsu, I. N., Jenkins, J. A. \& Blundell, T. L. (1978) Nature (London) 271, 618-621.

24. Andreeva, N. S. \& Gustchina, A. E. (1979) Biochem. Biophys. Res. Commun. 87, 32-42.

25. James, M. N. G., Sielecki, A., Salituro, F., Rich, D. H. \& Hofmann, T. (1982) Proc. Natl. Acad. Sci. USA 79, 6137-6141.

26. Overturf, M. L., Druilhet, R. E. \& Kirkendall, W. M. (1979) Life Sci. 24, 1913-1924.

27. Sealey, J. E., Atlas, S. A. \& Laragh, J. H. (1980) Endocrine Rev. 1, 365-391

28. Inagami, T. \& Murakami, K. (1980) Biomed. Res. 1, 456-475.

29. Leckie, B. J. (1981) Clin. Sci. 60, 119-130.

30. Hirose, S., Ohsawa, T., Murakami, K. \& Inagami, T. (1982) Exp. Brain Res. Suppl. 4, 53-63.

31. Inagami, T. (1982) Neuroendocrinology 35, 475-482. 